\title{
Facts on the Horizon: Future German Ink and Mineral Oil Ordinance. A National Approach and its European Spill Over: Risk Management, Compliance and Avoidance of Liability
}

\author{
By Matthias von Juterzenka* \\ Thomas Heupel
}

\begin{abstract}
In the wake of numerous food scandals, awareness has heightened very considerably and the German legislator has approved a bill of law that will improve protection for consumers ensure, consistent implementation of directives and on-the-spot controls on food and animal feed: The future German Ink Ordinance yet to come 2017/18. This article aims to give an overview of the current status of the German Ink and Mineral Oil Ordinance still to come in relation to recent and future risk management according to the liability risk of the regulation's future content. The theoretical goal of this paper is to narrow the gap between existing knowledge about present product liability due to migration from the paper based packaging and give recommendations for action towards adjusted and suitable behaviour due to the national regulation still to come. The possible European spill over will be highlighted. The recommendations for action set out in this article are suitable for company's risk management and provide guidelines for early adopters.
\end{abstract}

Keywords: Boiling Frog Syndrome, German Ink Ordinance, Liability, Packaging

\section{Introduction}

Nowadays, food retailers and grocers offer consumers a wide-open choice. In this respect, the packaging is the principal means of communication, distinguishing the product from its competitors and provoking the decision to buy. The packaging therefore, serves as protection during transport and storage, prohibits spoilage and ensures hygiene. It is carrier for information for usage, serves as sales promotion and an advertising factor at the place of sale. More than $95 \%$ of all groceries packaging that are put on the market in Western Europe are packaged. For ecological and economical purposes, paperbased packaging-material is largely produced using recycled paper. Swiss studies have shown that cardboard boxes made from recycled material can contain significant portions of mineral oil ${ }^{1}$. The mineral oils stem from printing

${ }^{*}$ Catholic University San Antonio (UCAM), Murcia, Spain and FOM University of Applied Sciences, Essen, Germany.

'FOM University of Applied Sciences, Essen, Germany.

${ }^{1}$ Biedermann and Grob (2010) 785. 
ink which is commonly used in newspaper printing. Frequent intake of such contaminated foodstuffs can thus lead to excess in the toxicological limit values. Animal studies in the 1980s have shown that mineral oil mixtures with low viscosity are stored in the body and can lead to accumulations and damage in the liver, heart valves and lymph nodes. Currently there are no studies on the effects of mineral oil traces on humans, but it cannot be ruled out that this fraction contains carcinogenic compounds. The increase in the number of foodpackaging migration alerts in recent times has been highlighted by consumer protection organisation and the media and the German legislator has decided to act.

The literature discusses paper-based packaging as an isolated issue in the field of packaging technology. Existing literature rarely provides knowledge about effects of the structural alterations stated before. The recent situation is discussed only between the German lawmaker and non-governmental stakeholders like industrial associations, panel discussions in conferences and highlighted by the media in case of food scandals like ITX in Baby milk or mineral oil traces in Advent calendars. In contrast to plant-protection product residues (Pesticide), traces of mineral oil in food and feed are not part of the focus from end customers. Due to this unobserved, concealed proceedings it is not an isolated case that companies may not be prepared for opportunities and risks.

The article describes the effects of decisive changes on this national industry branch and its effects on the European and domestic market, as German packaging meets requirements in 2017/2018. The Printer and packager will take on a portion of liability trough a declaration of conformity. The market is huge. A 2013 survey by the European umbrella organisation of European Carton Makers Association (ECMA) puts the market share for the German cardboard industries by $25 \%$ with a production value of $1,879 \mathrm{Mrd}$. Euros. The entire European corrugated industry had a sales volume of 4,730,760 $\mathrm{T} €$ and a turnover of 4,691,473 $\mathrm{T} €$ in corrugated board.

Up to now, EC paper and carton board were not regulated. A national regulation may be enacted regarding health issues. The time of transmission, that is the duration of time for adjustment and inventory reduction, will run out in approximate two years. After this timeline packaging for food- and feedstuffs must meet the German consumer-goods ordinance (BedGgsV). These changes come quietly, being discussed only in experts-circles and conferences, without much public interest. During the last years same scientific articles and economic reviews focused on the problematic use of recycled paper-fibres or migration of mineral oil traces, whiles others concentrate on documentation and compliance. This article seeks to illustrate the "big picture" and to describe the impact and consequences for producing companies.

The study underlying this article conducted a research design including the selection of participants and inducting them into the research processes and introducing the participants to the interviews by pre-tasking, drafting and executing the interview and obtaining feedback on the interviewees for validity (respondent validation or member checking). To recruit participants 
exponential discriminative snowball sampling was the method of choice, contacting one participant via the other. The study used this sampling method because the sample for the study is very rare and is limited to a very small subgroup of all actors in the fibre based packaging supply chain. A total of 41 respondents were found by snowball sampling and promised to take part. After uniform pre-tasking, a sample of 18 respondents agreed again to take further part for expert interviews. The interviewees were representatives of the most central actors in the decision-making process: 18 senior managers on CEO, CSO or COO level, chairman of industrial associations on German and European level. The research consisted of five focus groups: Industrial associations $(n=5)$, suppliers of raw materials for fibre based packaging $(n=3)$, packaging supplier $(n=5)$, food manufactures on European level $(n=2)$ and consultants $(n=3)$. The expert interviews were semi-structured in that they aimed at answering a similar core set of open questions for each case. They were used to fill gaps in the literature review, document trail and to ask for clarifications of complex matters. The face to face interviews $(n=15)$ and via telephone $(n=3)$ have lasted about 30 minutes and have been conducted in German or English. The interviews covered the period from February to April 2015; the single duration was about 32 minutes and a total of almost 47,000 words transcripts. The qualitative analyse of opinions and attitudes were done with QDA-Software MAXQDA Version 11.

\section{Paper-Based Packaging}

The close relationship between food and packaging also implements consensual subordination towards stringent regulations. Food contact materials are all materials and articles intended to come into contact with food, such as packaging and containers, kitchen equipment, cutlery and dishes. The safety of these materials must be evaluated as molecules can migrate from them into food. The expectations of the customer for consumables are a high level of pleasure, long imperishability, a low price, without a health risk for the consumer, with an ecological compatibility of the packaging and the production process. The packaging therefore, serves as protection during transport and storage, prohibits spoilage and ensures hygiene. It is carrier for information for usage, serves as sales promotion and an advertising factor at the place of sale. Paper-based packaging has many faces and it is best described as a coordinated system of preparing goods for transport, distribution, storage, retailing, and use. Packaging is an entity of components with the obligation to serve predictably and to cover a certain product. Packaging must ensure its ability to transport and store materials as well as transmitting information. As far as packaging is concerned to food and feed it is primarily related at protecting the content by maintaining its properties. For ecological and economical purposes, paper-based packaging material is largely produced using recycled fibres for paper and board manufacturing. According to national and EC regulations, it is the manufacturer of the food packaging and 
the marketer of food who are responsible for compliance with the law, but the Framework Regulation does not cover paper and board, not a single specific regulation. Paper and board are not synthetics based on cellulose.

\section{Migration of MOSH and MOAH}

As to food, feed and human health safety, packaging paper and board in general has to meet specific, characteristic requirements, to be characterised as suitable for its direct contact with foods. Recycled paper and board may contain many potential contaminants, which may migrate from packaging materials into foodstuffs. Migrants are substances which are able to be transferred through a material layer. This is based on to their chemical, mobile characteristics and molecular size; they diffuse across the packaging material. Recent research by Biedermann and Grob ${ }^{1}$ has shown that cardboard boxes made from recycled material can contain unexpected, significant high portions of mineral oil. Mineral oils include a wide range of hydrocarbon substances and are generally divided into mineral oil saturated hydrocarbon (MOSH) and mineral oil aromatic hydrocarbon (MOAH). As a rule, mineral oil enters the recycling process via stem from printing ink (mineral oil-based) generally used to print newspapers.

The Scientific Committee on Food (SCF) of the European Food Safety Authority (EFSA) consider the entire range of molecular weight of less than 1,000 Daltons (Da) to be toxicologically relevant because it can be absorbed through the human gastrointestinal tract. The hydrocarbons under cover duration for MOSH and MOAH fulfil this criterion. The statements or scientific opinions from official national or European authorities vary between "... identified potential concern...", "... The MOAH fraction may be both mutagenic and carcinogenic...", "...because of its potential carcinogenic risk, the CONTAM Panel considers the exposure to MOAH through food to be of potential concern..." and "... Today's opinion does not identify any specific food safety concerns." In summary, uncertainty remains.

\section{Mineral Oil is Ubiquitous - A Dilemma}

This knowledge is an ecological and economic dilemma, because government institutions and the Environment Agency at European level are very much in favour of promoting the use of renewable waste paper. As well as exposure to MOSH and MOAH by recycled fibres there are other sources of contamination. According to Matissek and Raters ${ }^{4}$ the origin of an environmental "body burden" of raw food materials with mineral oil

\footnotetext{
${ }^{1}$ Biedermann and Grob (2010).

${ }^{2}$ EFSA (2013) 6-7.

${ }^{3}$ FSA (2012) 1.

${ }^{4}$ Matissek and Raters (2012) 2.
} 
hydrocarbon substances can be related to the exhaust from gasoline engines, emissions from electric utilities and industrial facilities as well as fine dirt of asphalted roads. Another source of particulate pollutant inputs are lubricants from machinery for soil tilling and harvesting, from filling and packaging systems for the beverages industry and the food and non-food industry ${ }^{1}$. In conclusion we have established uncertainty based on origin, detection, method of proof and consequently due to compliance, regulations or guidelines too. One is faced with a perfect catch 22 situation.

\section{The Regulatory Framework}

With the increase in the number of food packaging migration alerts in recent times, highlighted by the media and resulting in withdrawals from market shelves, the German legislator has decided to act. On the $14^{\text {th }}$ of December 2010 the German Federal Ministry of Food, Agriculture and Consumer Protection directed a draft document towards several industrial associations. It was a draft law bill of the $21^{\text {th }}$ legal amendment of the Foods and Commodities Act (LMBG), specifically the Foods and Commodities Ordinance (BedGgstV), the German Ink Ordinance yet to come in 2017/18. This regulation may demand that packaging inks for packaging articles that come into contact with food can only be produced from lists of permitted substances and is aimed at controlling what is used in the packaging and has a potential for migration. The duty to comply with the migration components lies with the printer, packaging converter and the marketer. Migration of all listed substances migrating from the packaging, into the foodstuff must be below the specific migration limit (SML). A main initiator for potential migration is mineral oil from printing inks and recycled papers. The current situation is little known in the media and reports of problems remain rare because in politics and industries economic and ecological interests are adjusted in opposing directions.

In the EU there is still no harmonized regulatory framework on food contact paper, board and corrugated board applications. Especially for applications and on the use of recycled paper fibres in contact with food and feed, there is no specific directive about paper and board coming into contact with foods. The main underlying rules for paper and board food contact applications come from the EU Regulation (EC) No 1935/2004 and the Regulation on Good Manufacturing Practice (EC) No 2023/2006. The Framework Regulation applies to all materials or articles which, "in their finished state: (1) Are intended to be brought into contact with food; (2) or are already in contact with food and were intended for that purpose; (3) or can reasonably be expected to be brought into contact with food or to transfer their constituents to food under normal or foreseeable conditions of use." The essential safety requirement of the Framework Regulation is found in Article 3, which requires and demands that materials and articles, including active and

${ }^{1} \mathrm{EFSA}(2013)$. 
intelligent materials and articles, shall be manufactured in compliance with Good Manufacturing Practice (GMP) so that, under normal or foreseeable conditions of use, they do not transfer their constituents to food in quantities which could: (1) endanger human health; or (2) bring about an unacceptable change in the composition of the food; or (3) bring about a deterioration in the organoleptic characteristics thereof.

The German Inks Ordinance is structured along similar lines to the Swiss Ordinance SR 817.023.21, with a list of substances allowed to be used in the manufacture of food packaging inks, and migration limits for substances migrating from the printed packaging. Another focus will be put on so-called NIAS, non-intentionally added substances, that any kind of crosscontamination with other raw materials, consumables and supplies products is avoided under all circumstances. The compliance with legal requirements passes on to an upstream member of the packaging chain to the packaging company, co-packer and marketer. The notification process for EC legislation (law standards acceptable across the EU), a must when a national regulation has come in force, shall take place 2015, and the 2 years represent the transitional period for largely completed sale of foodstuffs and commodities that do not comply with the German Ink Ordinance still to come.

For nearly 4 and half years, both ordinances have been under construction and evaluated in the consultation phase of a law yet to come. Key issues of the $2^{\text {nd }}$ law bill of the Mineral Oil Ordinance (information and consultation December 2013) are: (1) no migration of aromatic hydrocarbons with carbon numbers range from $C_{10}$ to $C_{25}$ into food and feed; (2) evidence of migration potential in use of recycling, secondary packaging; (3) no evidence when migrations can be excluded (barrier principle); (4) new safeguards on margin of exposure; (5) a general barrier requirement for recycled cardboard, exceptions only if an absolute barrier can be demonstrated; (6) conformity confirmation for recycling packaging, no measurement of the food required (and not taking into account other sources).

\section{Critical Review}

The German Ink Ordinance in its current draft form has a number of shortcomings and disadvantages for paper based packaging companies. In fact of fast amendments of approved ink formulations the high degree of process reliability will be lost, but brand owner will be absolutely clear about their quality principles.

All regulations, at national or European level (incl. Swiss), are founded on the same recognized principle: No transfer of substances from packaging to food - and feedstuffs shall be permitted unless the substances are approved or harmless, or the concentration of migrants is below the specified limit. If this principle is not granted, a functional barrier is stipulated by existing law or law yet to come. Even if there are currently no regulations in force that related specifically to packaging made of paper and board or composites thereof 
(corrugated board), experts are for sure that the only matter of fact and of interest is which substances migrate in which concentration from a package to a foodstuff. No carcinogenic, mutagenic, repro-toxic substances may be used or detected.

This is very strange in an internal market if a law bill creates compositions that assume a peculiar state of suspension. From early findings to fixed margins of exposure for public health protection both regulations have been sitting idle for nearly four years and the related, subjected industrial branch behave in the same way as a boiling frog. This brings us to the question of whether the regulations will ever come into effect.

The popular right instrument to examine this question is issue management in our days. Issues management helps organizations to detect and respond appropriately to emerging trends or changes in the socio-political environment. These trends or changes may then condense into an issue, which is a situation that evokes the attention and concern of influential organizational publics and stakeholders. At its best, issues management is stewardship for building, maintaining and repairing relationships with stakeholders. Issues management and detection of weak signals are both, executive function that deals with problem solving, organizational policy, long-range planning, management strategy. Both involves looking into the future to identify trends and events which may influence the organization, because a changing mix of issues often creates a cumulate effect that managers and firms must face. The "old school" approach is Ansoff "Theory of weak Signals" which classified the occurrence of the signals, the so-called "states of ignorance under discontinuity". ${ }^{1}$ This approach has been chosen, because the very first signal is well known ${ }^{2}$. Political and economic fog of uncertainty makes it necessary to prepare and to arm a company and to reduce the response time to weak signals. Weak signals are based on the assumption that every event or disaster caused by man is at times to be foreseen and unsurprising. Under the auspices of discrete discontinuities in economic, political, technical and social affairs, they should take notice before they come into existence as a whole. As a common fact transmitter of Weak Signals use preferred media channels to spread. A particular problem is associated with less general ignorance of the human recipient, early warning indicators for the timely identification of irregularities and risk potential: (1) Interest rates and exchange rates; (2) population growth and structure; unemployment figures; (3) preparation of laws, future political stability; (4) information media area; spreading of opinions and position papers; (5) purchase price and condition, volume of supply and orders in hand (Figure 1).

\footnotetext{
${ }^{1}$ Ansoff (1975).

${ }^{2}$ Biedermann and Grob (2010).
} 
Figure 1. The Rise and Fall of Weak Signals

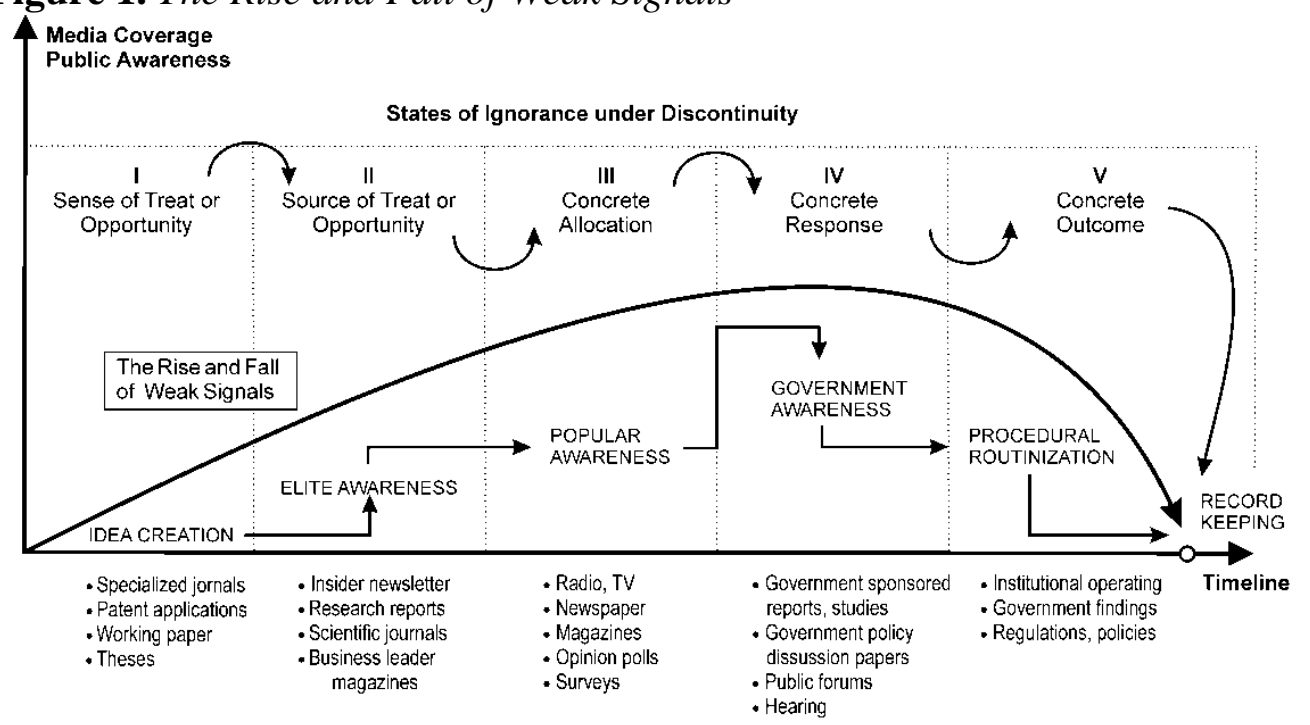

Source: Authors' Own Graph as an Extension of Hiltunen ${ }^{1}$

Inside direct professional-to-professional discussions and among industry insiders, the so-called "Mount of Olives" ${ }^{2}$ or in recent research "The Forest of Peaks" are well known. Sources of weak signals may have been specialized journals, patent applications, doctoral dissertations and early expert's discussions. Elite awareness took place. Hearings at the BMEL(V) and BfR took place; first internal findings were published in December 2009. The scientific community has been informed by Biedermann and Grob ${ }^{3}$. The characteristics, nature and the timing of impact are understood by the stakeholder, they recognise the existence, but a determined response is still ineffective or unworkable. These are solely perception of issue in the media and public. Political debate came into existence and statements of industrial associations are well known at this stage.

The weak signal expanded to its final state: A driving force which affects the whole of society. The weak signal is by now quantized and coded, the impact and consequences of response are computable by now. Hiltunen pointed out that at this stage government-sponsored report, studies of government policy discussion papers, draft legislation and law bills are on the horizon. ${ }^{4}$

In support of the above mentioned Ansoff's "states of ignorance under discontinuity", however it may be asserted, that both national German regulations will come into existence. The courses of events have already reached a concrete outcome. Ansoff predicted that a gap of some years is likely between the stakeholder first pick up of new, weak signals and crafting, executing and implementing of a new strategy. ${ }^{5}$

\footnotetext{
${ }^{1}$ Hiltunen (2008) 24.

${ }^{2}$ A so-called chromatographic "hump", colloquial named "Mount of Olives".

${ }^{3}$ Biedermann and Grob (2010)

${ }^{4}$ Hiltunen (2008) 2.

${ }^{5}$ Ansoff (1975).
} 
In view of the conditions of uncertainty concerning liability and limitation of liability of the marketer and supplier, the behaviour of supervisory authorities and the stakeholders' attitude towards the facing of the situation may be described as a wait-and-see attitude or a "paralysis by analysis" situation ${ }^{1}$.

\section{A European Response or Spillover?}

Since the first disputes in 2010, all stakeholders and involved parties would prefer a European-wide approach. In the light of these considerations, DG $\mathrm{SANCO}^{2}$ concludes that, from a legal point of view, there is no reason to give priority towards the German national approach, and no need or interest for regulation.

1. The very most fundamental, underlying law relating the safety of food contact materials in the European Union is the Regulation EC 1935/2004. The overall spirit of Article 3 is deliberate because it deals with the issue of the transfer of substances (migration) from food packaging materials into food. It also requires proof that the concentration of the substances in the food is at a level which will not pose a risk to the health of the consumer from the vantage point of the present knowledge.

2. The EC 2023/2006 on good manufacturing practice (GMP) sets out general demands for materials and articles intended to come into contact with food, and apply to all the categories of materials identified in Annex I of the Framework Regulation. It also applies to combinations of those materials and articles and to recycled materials and articles used in those materials and articles. It therefore clearly applies to paper and cardboard and to multilayer structures containing paper and cardboard. One of the most significant elements in the GMP Regulation is the requirement that starting materials must be selected to comply with pre-established specifications. These specifications must ensure compliance of the material or article with the rules applicable to it.

3. In order to limit the negative impact of contaminants in food and to prevent the risks to human health, the European Union (EU) is taking measures to reduce the level of contaminants in food. Council Regulation (EEC) No 315/93 laying down Community procedures for contaminants in food. Article 2 states "... food containing a contaminant in an amount which is unacceptable from the public health viewpoint and in particular at a toxicological level shall not be placed on the market...", and furthermore, "... contaminant levels shall be kept as low as can reasonably be achieved by following good practices at all the stages referred to in Article 1."

\footnotetext{
${ }^{1}$ Harremoës et al. (2001) 181..

${ }^{2}$ Acronym for the Directorate General for Health and Consumer Affairs.
} 
4. Regulation (EC) No $\underline{178 / 2002}$ ensures the quality of foodstuffs intended for human consumption and animal feed. Food shall not be placed on the market if it is unsafe and shall be condemned if it is considered to be injurious to health unfit for human consumption. In allocation whether any food is unfit for human consumption, regard shall be had to whether the food is unacceptable for human consumption according to "...reasons of contamination, whether by extraneous matter or otherwise, or through putrefaction, deterioration or decay."

The above mentioned regulations demonstrate the legally important aspect that national authorities are enforced on European level. They can act in conformity with existing laws or collective agreements or other jointly agreed arrangements. Consequently, there is no need to act.

The EU has only to consider whether there is opposition to EU law or follow-up at EU level. Member States may at any time set more stringent limit values or set limit values for other substances and parameters.

Only Austria has a recommendation published for the use of barriers and no other Member State has developed activities. For that matter the German BMELV fully acknowledges the need for a separate national approach.

Figure 2. Expected Paradigm Shift

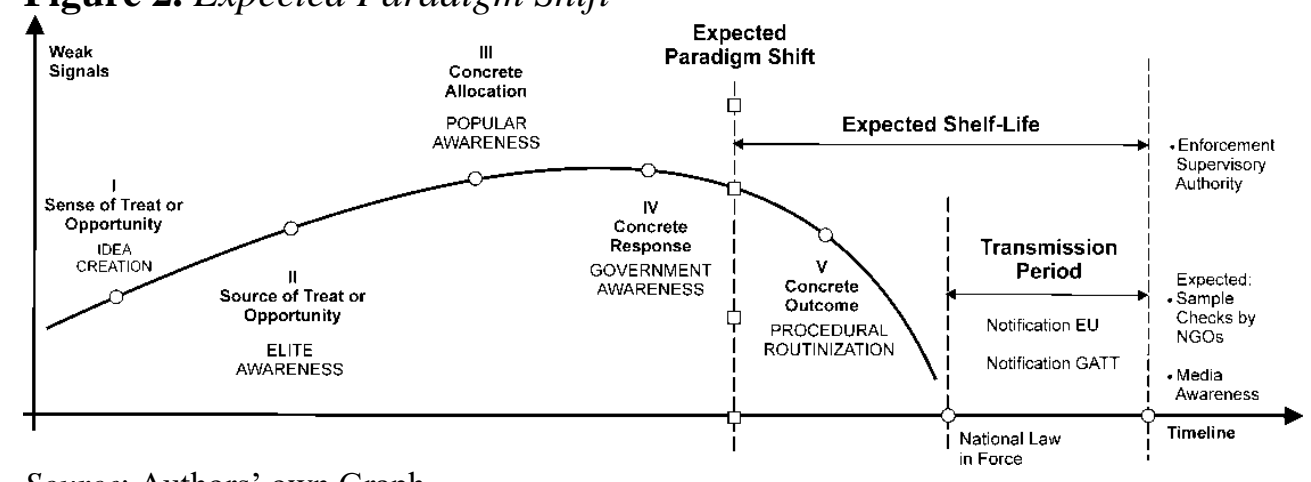

Source: Authors' own Graph

The EU Directorate SANCO has refused to start regulatory process. This decision may be for financial reasons or due to insufficient time and resource scarcity, respectively. It can also be assumed that they know what it means to regulate a ubiquitous substance with multiple use characteristics like MOSH and MOAH.

Both the German and the European regulator may have one thing in common: that is a "sit and wait" attitude. The interesting question is, however, why they agree on this issue? Why does the industrial branch behave like a boiling frog? ${ }^{1}$

\footnotetext{
${ }^{1}$ The boiling frog is a scientific, urban legend or myth. The parable states that a frog thrown into a pot of boiling water will quickly jump out. But a frog thrown into a pot of temperate water may stay even if the temperature is slowly raised to boiling, leading to the untimely demise of the frog. Allegedly, the frog is not able to determine the gradual increase in
} 
From a German perspective, the proposal on mineral oil in food packaging is a national approach - though a common approach is more effective. In the international context, Swiss authorities for example just regulate the characteristics of inks, the ingredients of manufacturing, methods and the utilisation of selected substances used for food packaging. Austria, contrarily, has just given a non-legally binding recommendation.

The date of the expected German paradigm change may be subjected to the bargaining power of buyers or bargaining power of customers; on the other hand by threats of substitutes, specially-sealed flow wrapping packaging versus paper based packaging.

Is the fixed date of minimum durability of foodstuffs before the beginning of the transmission period, the expected scenario will take place earlier, inventory and market clearances must take place before the end of the transmission period. It may be assumed that at this turning point the late majority will have been committed towards new regulations. If laggards are still in the field, they may focus on leaving the market or may bear high costs to overcome market entry barriers in short time. The late majority and the laggards benefit from the extension of the transmission period. Everyone else will be the losers like the innovators, early adaptors an early majority, they do not gain a first mover advantage. For that reason the "sit and wait" behaviour may be succeed.

The first weak signals of the yet to come paradigm shift (Figure 2) might be located upstream within the packaging supply chain; specific reference may be made here towards the suppliers of raw materials. Many paper and board producers currently tend to optimize existing machines and improve their runability in combination with suitable surface coatings.

They offer a functional barrier, inline coated on recycled fibres. Ink manufactures, for example offer low migration inks before they are forced by law. In a nutshell upstream suppliers enhance and secure their inverter delivery capacities before the shift of paradigm. Research recently carried out by Simat ${ }^{1}$ shows firstly that from 2010 to 2013 there has been a steady growth of fresh fibres instead of recycled fibres.

Moreover, it is discovered that substitution occurs from paper based packaging towards sealed bags and stand-up pouches. Like facts, weak signals are on the horizon.

At the European level, there is no need to regulate. Proper implementations of framework regulations are done and with respect to the existing legislation, every member state can act in behave of public health.

For Europeans means that they must find answers and think through properly, when an "island solution" may arise due to the possible German market yet to come. Market entry barriers subjected to the barrier principle and conformity assessment (declaration of compliance). For companies, the EU

temperature until it's too late for him. The boiling frog syndrome is a cautionary warning against complacency; an excellent metaphor for the human tendency to ignore the consequences of negative change if that change happens gradually.

${ }^{1}$ Simat (2013). 
internal market without national frontiers is a source of reliable and competitively priced supplies, but by now one is forced to craft and execute a three-road strategy. At first one can split the market into two segments - i.e. an EU-wide internal market with or without the inclusion of the German market because there are no exit barriers except revenue and economy of scales in production. It can be assumed that the German market for paper based packed food is too big to fall, and that the loss of economies of scales effects and thus, unnecessarily increases the associated costs as well as sales risks.

On the other hand food manufacturers/operators can be early adapter and broaden the range of German paper-based packaging all over Europe. In this case two kinds of packaging quality are in the market; and on top all that, this hallmark of quality is may not know to the customer and is not meaningful due to sale, no properties of search and experience. The outcome of the proceedings is for sure, a "lemon problem", the good quality will not succeed. At last we can assume that by analogy as regards to sectorial crises (BSE crisis, Foot-andMouth Disease) linked to economic restructuring, German regulations may push EU jurisprudence, which needs to be founded by a mutual European solution.

The key assumptions postulated above concerning the future and other key sources of paper-based food packaging in the EU may lead to the question when it is time to move?. Is there a change of paradigm at a European level too?

In view of the assumption of the postulated lemon problem, early adaptors and the early majority will not succeed. Yet, all actors that perform a second mover strategy will do. As a hypothesis, the optimum for a European turning point is the end of the transmission period, the gross time less the time required for adjustments to production and compliance. As always, the devil is in the detail, and it should therefore be expected that much work remains to be undertaken in the EU and Germany for a substance-based risk management due to paper-based packaging. Yet, both postulated hypothesis differ only with regard to the assigned time of likelihood of their occurrence and to their quantitative impact.

\section{Recommendations for Actions}

The recommendations in the following section refer to all potential parties in the packaging supply chain, upstream to the suppliers of ink, lacquer, paper, glue etc. and downstream to the retailer or brand owner. Representative in this example will be the ink manufacturer as a supplier of crucial base materials. His delivery and contractual situation is absolutely comparable with other suppliers in the entire production chain of paper based packaging. Particular attention is paid to the fact that the ink industry is subject to intensive observation by the legislator. The upstream contract partner for the packaging company still to come in the packaging chain is the grocery producer. He is the one who fills the box, tray or shipper with food or animal feed, sealed in a 
pouch or unpacked. In this legally significant moment the common box transforms into a food packaging, just like a transfer of risk. The packaging manufacturer avoids under all circumstances, through suitable terminology, to allow a definition of his declaration of conformity that would indicate an inference of warranty on the side of the packaging manufacturer, or rather, it has to be his overall goal, to rule out any interpretation as a declaration of warranty through proper wording. A warranty is a contract between a buyer and seller which guarantees the buyer a definite right to compensation. In a legal sense a warranty defines a contractual responsibility of the guarantor, in this case the packaging manufacturer. This no-fault, strict liability presents a high economic risk. The grocery producers distribute their products to the markets, and the merchants distribute the packaged food products to the consumers. It can be assumed that at this level no declarations of conformity are issued any more to each other. It may be useful to note that there is mutual trust in quality in major retail chains or the high level of expectation towards brand owners. The next commercial trading partner in the supply chain is the merchant. He advertises or offers the intention to sell foodstuff to a customer. By advertising the merchant expresses an invitation for other people to submit offers. If a customer accept the merchant's invitation by coherent behaviour (paying for at supermarket's cash registers), he is bound by a contract. Right now must be considered, that each party of the contract must receive something of value: the merchant the money, the customer the good. If the buyer is buying foodstuff for consumption in a particular intention, there is an "implied term" that the goods are fit for that and must correspondent to that purpose, if not, the end customer exercise any legal claims towards the merchant or brand owner. End-customers enforcement of liability against the merchant will be passed through to the grocer and causally linked to the packaging company.

In addition a high common level of consumer protection takes place, in particular through the establishment of common consumer protection regulations and the integration of consumer interests into other community policies and ordinances, enforces the system from "farm to fork" including packaging and its supply chain. Public veterinary offices as the local food inspection board work in silence, but diligently towards turns of inspection.

Based on the contractual relationships outlined in general above, two disastrous scenarios for damage claims can be deduced. After a food producer has distributed his products on the market, through analysis by, for example, a consumer safety organization, it is determined that non-evaluated (therefore considered toxic) substances from the printing ink have migrated into the food product, or that substances that endanger human health are found in the food product. In both cases the food producer recalls his already delivered products, suffers massive financial damage and will do everything, to get compensation from the packaging manufacturer. The brand owner or marketer demands indemnity. Also, the end-user (consumer) will suffer damages after consuming the product and will also demand compensation from the brand owner, that demand will still be transferred to the packaging manufacturer. 
From a strategic supplier standpoint the packaging supply chain is by now subjected to the final state of ignorance; the concrete outcome and the procedural routinisation are close at hand. Owing to this fact, a shift of paradigm may be expected and a trend towards packaging that meets statutory requirements yet to come. The point in time can be calculated when the enforcement of the supervising authority and additional expanded inspection referred to NGOs will take place: it is the end of the transmission period, including or excluding the expected minimum shelf life date or consumption date of packed food or feed within the modular packaging on the whole. According to recent national and EC regulations, it is the manufacturer of the food packaging and the marketer of food who are responsible for compliance with the law, but the Framework Regulation does not cover paper and board yet, not a single specific regulation. Paper and board are not synthetics based on cellulose.

The liability of a packaging manufacturer can always be understood under the premise of negligence, when migration or visible set-off were foreseeable and avoidable. No matter how much care is taken migration of printed layers can occur by invisible set-off during stacking on piles. GMP-guidelines and process instructions are the common tools for a company's precautionary provision. The base for good GMP is good, gapless documentation: (1) information about up-stream processing stages and pre-suppliers, including certificates of suitability; (2) recipes, migratory potential, process control data and GMP documentation; (3) internal test results and third party test results; (4) internal calculations; (5) certificates from third parties to comply; (6) analysis reports from third parties; (7) internal risk assessments; and (8) worst case scenarios. With regards to GMP and QS-regulations these risks are limited and will be technically and economically controllable for most concrete applications in printing and packaging. Because a portion of the risks lie outside the company's influence, even a functioning risk management system cannot completely rule out all risks, therefor further-reaching liability must be ruled out on any legal grounds. This pertains in particular to the duty to provide information and subsidiary obligations belonging to the printing and packaging contracts, if the packaging specifications on the proposed goods are known, but an agent or employee fails in doing the required actions properly.

In spite of everything an expert opinion and industrial guidelines do not eliminate the potential risk of recall and initial compensatory payments. In the context of averting a danger this remaining risk must be shifted to another business operator. Reducing the residual risk to an acceptable level demands a contracting insurance to cover acts of God or human misconduct or stupidity. It is prudent for a company to extend the general liability cover to product liability for damage caused by defective products and to additional coverage to pay the costs of recalling a product from the market. Recall costs and product liability are insurable.

From the perspective of Fiedler and Hoffmann ${ }^{1}$, and Kersten et al ${ }^{1}$ possible recommendations for action, approaches and a variety of options have been

${ }^{1}$ Fiedler and Hoffmann (2013) 5, 
discussed: (1) low migration inks; (2) prohibition of waste paper for food packaging; (3) encourage substitution by virgin fibres; (4) improvement of the recycling process; and (5) the use of a functional barrier or coating. All approaches cannot be effectively and promptly implemented and they are neither economically nor ecologically meaningful in the present state of affairs. Due to the absence of guidelines and safeguards at present time, the overarching principle behind these requirements is the avoidance of liability risks, internally and externally: (1) comprehensive consultation in the packaging supply chain; (2) overall assessment of raw materials, packaging and finished products; (3) own due diligence faced realistically and compliance with laws or regulations; (4) necessary diligence (migration test); (5) review of the contracts governing, limitations of liability of the suppliers, given warranties, rules of evidence and adjusting the insurance cover.

\section{Conclusions}

The pollution of waste papers with $\mathrm{MOH}$ is incorporated in our current recycling system and will remain for several years to come. The uptake of substances from the environment, mainly through accumulation in the food and packaging supply chain, can hardly be avoided. Instead of using paper-based boxes with functional inner pouches for food and animal feed, one can conclude that it may be suitable to print directly on the non-contact surface of an absolute barrier, such as flow-wrappings of multi-layered plastic materials which are stored in a common tray. This opportunity has the potential to redefine whole branches of current industry related to papermaking and paperbased packaging.

Henry Kissinger once famously remarked: "An issue ignored is a crisis invited". Weak signals have been spread and highlighted and investigated by the media. German national authorities take a position on the content of mineral oil migration into food. Highlighted by the media, this issue was resonated and recommended for discussion in politics. The pollution of mineral oil is ubiquitous. It is omnipresent in food and feed, food contact materials and the political wish is that Europe must aim for a closed circle economy. The issue cannot be solved just by modifying packaging.

\section{References}

Ansoff, H.I. (1975). 'Managing strategic surprise by response to weak signals'. California Management Review 2 (XVIII Winter): 21-33.

Biedermann, M, and G. Grob (2010) Is recycled newspaper suitable for food contact materials? Technical grade mineral oils from printing inks. European Food Research and Technology 230(5): 785-796.

\footnotetext{
${ }^{1}$ Kersten et al. (2011) 15.
} 
EFSA-Panel on Contaminants in the Food Chain (CONTAM) (2013). Scientific opinion of the CONTAM Panel: Mineral oil hydrocarbons in food. EFSA Journal. Available from: http://bit.ly/1EcsV5C [Accessed: 24 April 2015].

Fiedler D. and S. Hottmann (2013). 'Verhinderung der migration von mineralölen aus druckfarben und recycling durch einsatz von adsorbierenden substanzen in der strichschicht' [Prevention of the migration of mineral oils from printing inks and recycling through the use of adsorbing substances in the coating layer]. PTSForschungsbericht IK-MF 100094. Papiertechnische Stiftung PTS. Available from: http://bit.ly/1EnlYAW. [Accessed: 24 April 2015].

FSA-Food Standard Agency (2012) Food Standards Agency - Response to EFSA Opinion. Available from: http://bit.ly/1P5yxDC [Accessed: 24 April 2015].

Harremoës. P., Gee, D., MacGarvi, M., Stirling. A., Keys, J., Winne, B. and S.G. Vaz (2001). 'Late lessons from Early Warnings. The Precautionary Principle 1896$2000\left(1^{\text {st }}\right.$ Ed.). Environmental issue report (22) Copenhagen: Office for official publications of the European Communities. Available from: http://bit.ly/1bCHDLv [Accessed 24 April 2015].

Hiltunen, E. (2008) Good sources of weak signals: A global study of where futurists look for weak signals. Journal of Futures Studies 12(4): 21-44.

Kersten. A., Hamm, U., Putz, H. J. and S. Schabel (2011). 'Zur diskussion um die migration von mineralöl in lebensmittel und das altpapier-recycling'. [For discussion of the migration of petroleum into food and the recycling of old paper]. Wochenblatt für Papierfabrikation (1): 14-21.

Matissek, R. and M. Raters (2012) Mineralölrückstände in lebensmitteln. MOSH und MOAH [Petroleum residues in food. MOSH and MOAH.] Süsswaren (5). Available from: http://bit.ly/1Kt32mi [Accessed: 24 April 2015].

Simat, T. (2013) Recycled Fiber in Food Contact - Trends in the Market. $3^{\text {rd }}$ International Fresenius Conference. TU Dresden. Cologne: Die Akademie Fresenius GmbH. 